\title{
Reagent Activated Cotton Fiber for Rapid Determination of Aldehydes in Diverse Matrices
}

\author{
S. Tantry*, K. Tharpa*, Ajay Kumar*, Arun Kumar* and B.H.S. Thimmappa**† \\ *SABIC Research \& Technology Pvt. Ltd., Plot No. 81 to 85, Chikkadunnasandra, Sarjapura-Attibele State Highway, \\ Bengaluru-562125, Karnataka, India \\ **Department of Chemistry, Manipal Institute of Technology, Manipal Academy of Higher Education, \\ Manipal-576104, India \\ †Corresponding author: B.H.S. Thimmappa; bhs.thims@ manipal.edu
}

Nat. Env. \& Poll. Tech. Website: www.neptjournal.com

Received: 02-09-2020

Revised: $01-10-2020$

Accepted: 06-11-2020

\section{Key Words:}

Reagent activated cotton fiber O-benzyl hydroxylamine (OBA)

Formaldehyde

Acetaldehyde

Diverse matrices

\begin{abstract}
A method to capture and analyze aldehydes in either solution or gas samples on cotton fiber, activated with O-benzyl hydroxylamine (OBA), is developed. The stability of the reagent activated cotton fiber (RACF) with and without capturing aldehydes was 17 days and $24 \mathrm{Hrs}$, respectively, qualifying the technique for field applications. Thus the aldehyde capturing can be done outside the lab using RACF in any closed environment and bring back to the lab for the quantitative analysis.. The analytical method is based on the gas chromatographic analysis of aldoxime formed between aldehydes and OBA on RACF. Optimized experimental conditions required $50 \mathrm{mg}$ of RACF to capture aldehydes with a reaction time of 15 minutes. The technique detects aldehydes much below the permissible exposure limits of $25 \mathrm{ppm}$ for acetaldehyde $\left(\mathrm{CH}_{3} \mathrm{CHO}\right)$ and $0.75 \mathrm{ppm}$ for formaldehyde $(\mathrm{HCHO})$. The method's detection limits are $4 \mathrm{ppb}$ of $\mathrm{HCHO}, 8 \mathrm{ppb}$ of $\mathrm{CH}_{3} \mathrm{CHO}$ in the gas sample, and $1.5 \mathrm{ppb}$ of $\mathrm{HCHO}$, and $19 \mathrm{ppb}$ of $\mathrm{CH}_{3} \mathrm{CHO}$ in the solution or aqueous sample. The analytical method was validated within the established quantitation ranges as per the required International Council for Harmonization Guidelines (CPMP/ICH/381/95). The RACF is a quick tool to measure aldehydes in a polymer sample, laboratory cupboards or refrigerators, and chemical products. The method described here complies with green analytical chemistry principles such as reduction in a solvent, chemical sample size and waste generation, cost-effectiveness, and usage of a biodegradable substrate.
\end{abstract}

\section{INTRODUCTION}

Simple aldehydes such as formaldehyde and acetaldehyde are building blocks of many essential chemicals of daily use. They are universal air pollutants sourcing from the air, water, and products such as paint, cosmetics, and plastics. Both monitoring and limiting the concentration of aldehydes in the air, workplace, and consumer products, are essential because they are known or suspected carcinogens as per the Evaluation of Carcinogenic Risks to Humans (WHOIARC 2002) More recently, there are many publications on the development of an aldehyde monitoring system using different sampling techniques and analytical methods suitable for measuring aldehyde in the air, water, or products (Szulejko \& Kim 2015). Using ortho-benzylhydroxylamine (OBA) as a derivatizing agent, the ppm level analysis of aldehydes in triethanolamine was developed, but it requires a long derivatization time (Jain \& Thielen 1995). Methods were developed using o-2,3,4,5,6-(pentaflurobenzyl) hydroxylamine hydrochloride agent (Nawrocki et al. 1996, Koziel et al. 2001), which involves a solid-phase extraction for the analysis of low-ppb amounts of aldehydes-ozonation by-products. The well-known reagent 2,4-dinitrophenyl hydrazine derivatization for determination of aldehydes in fish (Veloso et al. 2001) and simultaneous determination of ketoconazole and formaldehyde in shampoo (Vander et al. 2002) by high-performance liquid chromatography (HPLC) was studied. Formaldehyde is highly toxic, and the levels are regulated in many products, including cosmetics, textiles, household products, indoor work, and the environment. A simple and sensitive flow injection method with fluorimetry and 5,5-dimethylcyclohexane-1,3-dione (dimedone) was developed for the determination of formaldehyde (Sakaia et al. 2002). However, this needs a heating system for a longer time. The solid-phase microextraction technique combined with GCMS (Tsai et al. 2003, Qing et al. 2011) involves multiple steps and applicable to only water samples. Atmospheric pressure photoionization-mass spectrometry (APPI-MS) is used for the analysis of aldehydes and ketones after derivatization with 2,4-dinitrophenylhydrazine (DNPH) and liquid chromatographic separation (Suze et al. 2004), but 
this is not much linear to quantify in automobile and cigarette exhaust samples. Using pentafluorophenyl hydrazine reagent, determination of formaldehyde in cosmetics using combined headspace-solid-phase microextraction-gas chromatography (Rivero 2004) involves a tedious cleanup process. Japan has a water quality standard in place for formaldehyde levels in drinking water $\left(0.08 \mathrm{mg} . \mathrm{L}^{-1}\right)$.

Determination of aldehydes using 2,4-dinitrophenylhydrazine derivatization is well known, and the same is applied for the quantification of linear aliphatic aldehydes in water in the presence of heavy metals by HPLC (Lin et al. 2009). Derivatization using fluorescein 5-thiosemicarbazide through capillary electrophoresis is very sensitive to temperature and time. This technique is applied for the analysis of low-molecular-mass aldehydes in drinking waters using laser-induced fluorescence detection (Eugenia et al. 2010). Simultaneous determination of thirteen polycyclic aromatic hydrocarbons and twelve aldehydes in cooked food by an automated online solid-phase extraction ultra-high-performance liquid chromatography-tandem mass spectrometry (Gosetti et al. 2011, Guan \& Rubin 2012) was very promising. However, the observed matrix effect and the need for lots of solvent for washing of SPE sorbent makes it a technique of low practical value. Many methods have been developed using GCMS and LCMS. The new concept of a microfluidic lab-on-chip using o-2,3,4,5,6-(pentafluorobenzyl) hydroxylamine hydrochloride derivatizing agent for gaseous carbonyls analysis (Pang et al. 2013) was very promising and executed for a specific application. Reviews on formaldehyde gas sensors and analytical methods to assess carbonyl compounds in foods and beverages provided more insight into this area (Chung et al. 2013, Vanessa \& Zenilda 2013, Jeong et al. 2015). Formaldehyde quantification in hair straightening products was established using the proton nuclear magnetic resonance technique (NMR) (Kuballa et al. 2013). However, it is not sensitive for low-level detection, and the standard deviation was found to be very high. Solid-phase microextraction with fiber derivatization for the sampling of formaldehyde indoor involves the use of a combination of two reagents, and the stability of fibers is not found to be that effective. For determining aldehydes in the gas phase of mainstream smoke by headspace gas chromatography-mass spectrometry, PET bottled mineral waters and beverages, and derivatization techniques for determining carbonyls in the air/food/monomer samples was very useful but limited to specific matrices (Valentina et al. 2014). Determination of low-level aldehydes in detergents, cosmetic products, and airborne aldehydes in-cabin air of aircraft (Rosenberger et al. 2016) involves photoluminescence and HPLC detection, respectively (Gholami et al. 2016). Aerosol samples generated from e-cigarettes and tobacco smoke were collected manually using 2,4-dinitrophenylhydrazine (DNPH) cartridges at a constant sampling (puffing) velocity of $1 \mathrm{Lmin}^{-1}$ or another, and the result was directly linked to the number of puffs and consistency in reproducing the same (Sang et al. 2016, Mumiye et al. 2017, Zhao et al. 2017, Zhang et al. 2018). In a few cases, the analysis was not handy and involved expertise, and the techniques used also need modification for a particular application. Other challenges include interference from other pollutants, not user-friendly, not cost-effective, less sensitive mass analysis reproducibility, metric effect, and stability issues. No single technique is both economical yet sensitive and universal in its application to measuring aldehydes in all three types of samples. Further, so far, the use of reagent activated cotton has not been reported for such an analytical application.

We used pure dried cotton fiber activated with $O$-benzylhydroxyl for both sampling and analysis of aldehydes in the air, the solution, or the solid product. Besides low-cost cotton offers many advantages as an ideal sampling tool such as i) fast, uniform distribution and transportation of the reagents or the sample, ii) absorbs and hold reagents, iii) a large, lightweight network structure with large surface area to hold excess reagents, iv) withstands against external forces and v) natural, highly biodegradable, and disposable (Dochia et al. 2012). Upon optimizing all experimental conditions, we use just $50 \mathrm{mg}$ of reagent activated cotton to capture aldehydes from the air or solution sample and 15 minutes reaction time to form quantifiable aldimine products. The long hours of stability of the reagent activated cotton, as well as the captured aldehyde in the form of aldimine, enabled this technique to measure aldehyde in both laboratory environments and products. The captured aldehydes are analyzed by gas chromatography with flame ionization detection (GC-FID) as formaldehyde $O$-benzyl oxime and acetaldehyde $O$-benzyl oxime within the quantifiable range.

\section{MATERIALS AND METHODS}

\section{Reagents and Materials}

Aqueous solution of $0.1 \%(\mathrm{w} / \mathrm{w}) o$-Benzylhydroxylamine hydrochloride (Sigma Aldrich, India) and $0.01 \%(\mathrm{w} / \mathrm{w})$ benzyl alcohol (Sigma Aldrich, India) were prepared. Reagents such as $0.1 \mathrm{M}$ solution of potassium dihydrogen orthophosphate (SDFCL, India), 0.1 M solution of dipotassium hydrogen phosphate $\left(\mathrm{K}_{2} \mathrm{HPO}_{4}\right.$-Sigma Aldrich), $0.1 \mathrm{M}$ hydrochloric acid (Merck, India) were prepared in deionized Millipore water. About $36 \%$ (w/v) aqueous formaldehyde (SDFCL, India) was diluted as required, and n-hexane (Merck, India) was used as received. Acetaldehyde (Fluka, USA) was distilled at $40^{\circ} \mathrm{C}$ until its purity was $99.9 \%$ achieved on the GC-FID. Commercially available absorbent 
cotton (Indian or British Pharmacopeia grade) was used for all the experiments.

\section{Instrumentation}

A Shimadzu 2010 gas chromatography (GC) system was used for the study. The system is equipped with a flame ionization detector (FID), and an auto-injector which can be used for all types of analysis. A fused silica capillary column (DB210, Agilent) having a dimension of $30 \mathrm{~m}$ in length, 0.25 $\mathrm{mm}$ internal diameter, $0.5 \mu \mathrm{m}$ film thickness was used for the GC analysis. Helium was the carrier gas $\left(1.0 \mathrm{~mL} \cdot \mathrm{min}^{-1}\right)$. The column temperature gradient program was, first starts with $50^{\circ} \mathrm{C}$ isothermal for $1 \mathrm{~min}$, ramped up to $200^{\circ} \mathrm{C}$ at $6^{\circ}$ C.min ${ }^{-1}$ withholding time of $1 \mathrm{~min}$, ramped again at $25^{\circ} \mathrm{C}$. $\min ^{-1}$ to $220^{\circ} \mathrm{C}$, and held for 2 minutes. The injection port temperature was $225^{\circ} \mathrm{C}$, and the detector temperature was $250^{\circ} \mathrm{C}$, respectively. The split ratio was at $10: 1$, with an injection volume of 1.0 microliter.

\section{Methods and Procedures}

Distillation of acetaldehyde: The commercially supplied acetaldehyde, although stored under $8^{\circ} \mathrm{C}$, contains many impurities. Paraldehyde was found to be one of the major impurities. Therefore, the acetaldehyde was distilled at $30^{\circ} \mathrm{C}$ and collected in ice-cold water through a de-activated silica column. The set-up for acetaldehyde distillation is shown in Fig. 1.

Cotton pre-treatment: Cotton was repeatedly washed in water, followed by hexane and allowed to dry in the air for several hours. The dried cotton is referred to as pre-treated cotton and use for activation with the reagents.

Cotton activation: About $3 \mathrm{~g}$ of pre-treated cotton was dipped overnight in a $500 \mathrm{~mL}$ beaker containing $100 \mathrm{~mL}$ of $1: 1(\mathrm{v} / \mathrm{v})$ of $\mathrm{pH} 4$ buffer solution and $0.1 \% O$-benzylhydroxylamine (OBA) hydrochloride solution. The reagent activated cotton was dried in the air for several hours and used for the analysis of aldehydes in the air or aqueous sample. Since cotton has a high resistance to solvents and alkali, it will not react with any chemicals; however, due to its multilayered structure and better adsorption property (Textile Fashion Study 2012), it will hold the reagent for a longer time. The reagent $O$-benzylhydroxylamine (OBA) hydrochloride will be absorbed entirely and detected in the gas chromatography technique.

Physical and chemical properties of cotton before and after activation: Cotton, the seed hair of plants of the genus Gossypium, is the purest natural form of cellulose, containing more than $90 \%$ of the polysaccharide. It is a dominant natural fiber and recognized as a chemically and biologically inert material. Hence, in the chemical field, it showed positive results for inertness and is an eco-friendly material. After hexane washing and reagent activation, the color of the cotton was remaining the same as shown in Fig. 2.

Cotton has excellent resistance to degradation by heat, damage after $240^{\circ} \mathrm{C}$ due to oxidation. The blank runs using

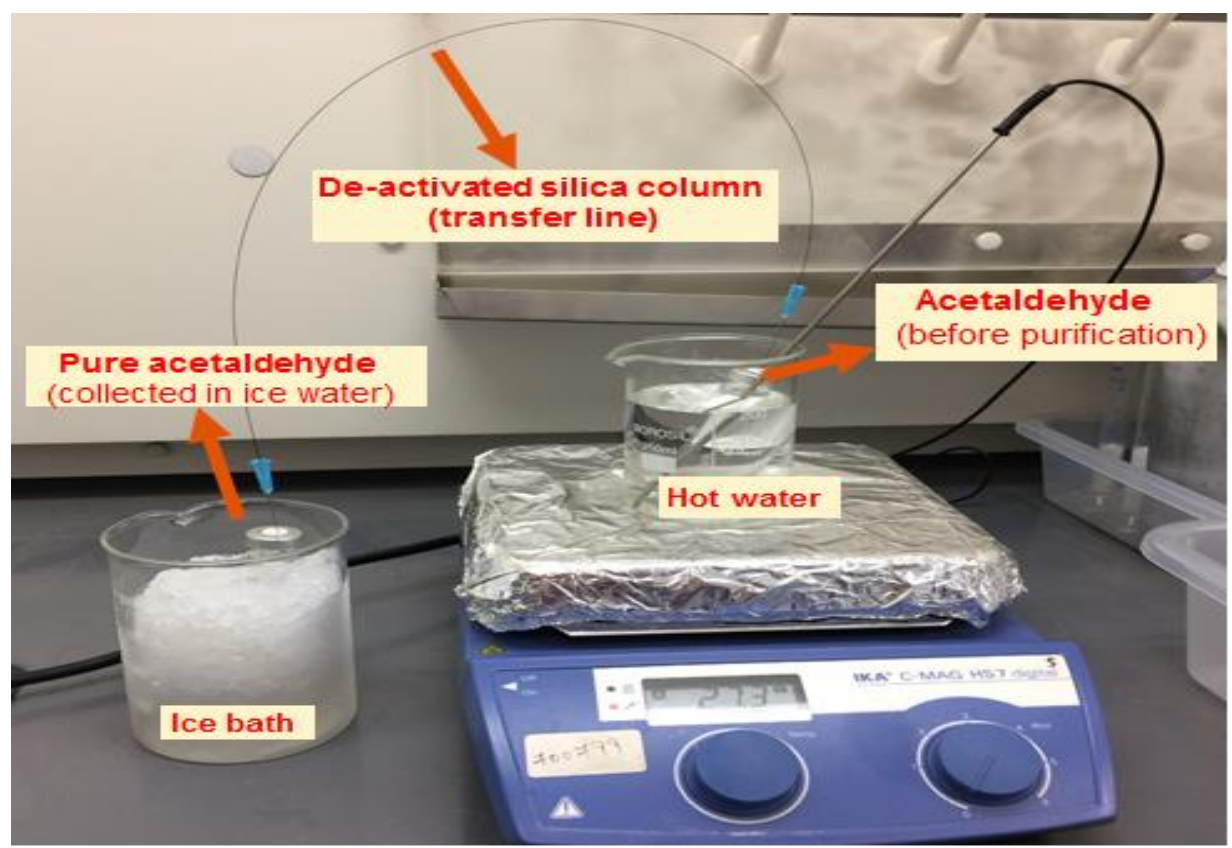

Fig.1: Acetaldehyde distillation. 
reagent activated cotton fiber did not show any new peaks during GC-FID analysis, as shown in Fig. 3.

\section{Calibration of Aldehydes in Vapor and Solution States}

Calibration of aldehydes in vapor state: About $50 \mathrm{mg}$ of reagent activated cotton taken in different headspace vials were crimped and connected using deactivated fused silica capillary transfer line to another set of crimped headspace vials containing varying concentrations of aldehydes. Deactivated fused silica capillary columns will play a very vital role in gas chromatography for trace analysis of polar/low boiler components since they will not interfere with any chemical components in the sample matrix. For aldehydes calibration, formaldehyde and acetaldehydes in the range of 0.1 to $1 \mathrm{ppm}$ are prepared in water. The headspace vial containing aldehydes was heated in an oil bath at $90^{\circ} \mathrm{C}$, and the resulting vapor was collected in a vial containing activated cotton for one hour. Later, the reagent activated cotton was transferred into a series of polypropylene (PP) tubes, and each PP tube had an added $1 \mathrm{~mL}$ of $0.01 \%$ benzyl alcohol as the internal standard, $1 \mathrm{~mL}$ of $0.15 \mathrm{M} \mathrm{H}_{2} \mathrm{SO}_{4}$ and $1 \mathrm{~mL}$ of $n$-hexane solution and vigorously shaken for $1 \mathrm{~min}$. The $1 \mathrm{~mL}$ of the hexane layer was analyzed using the method described in section 2.2.

Calibration of aldehydes in the solution state: The same procedure was followed as in vapor state calibration, except that the different concentration of aldehydes was directly added to the reagent activated cotton.

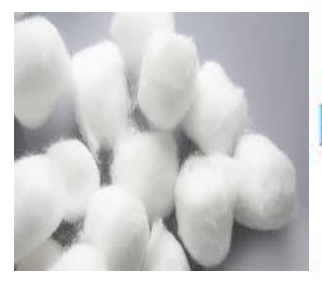

Raw/IP/BP cotton

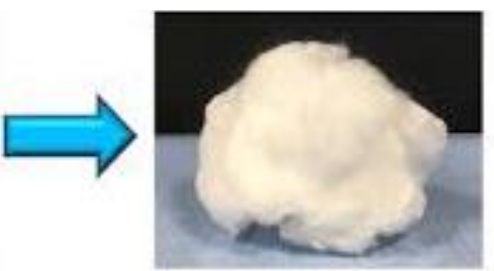

Reagent activated cotton

Fig. 2: Cotton before and after activation process.
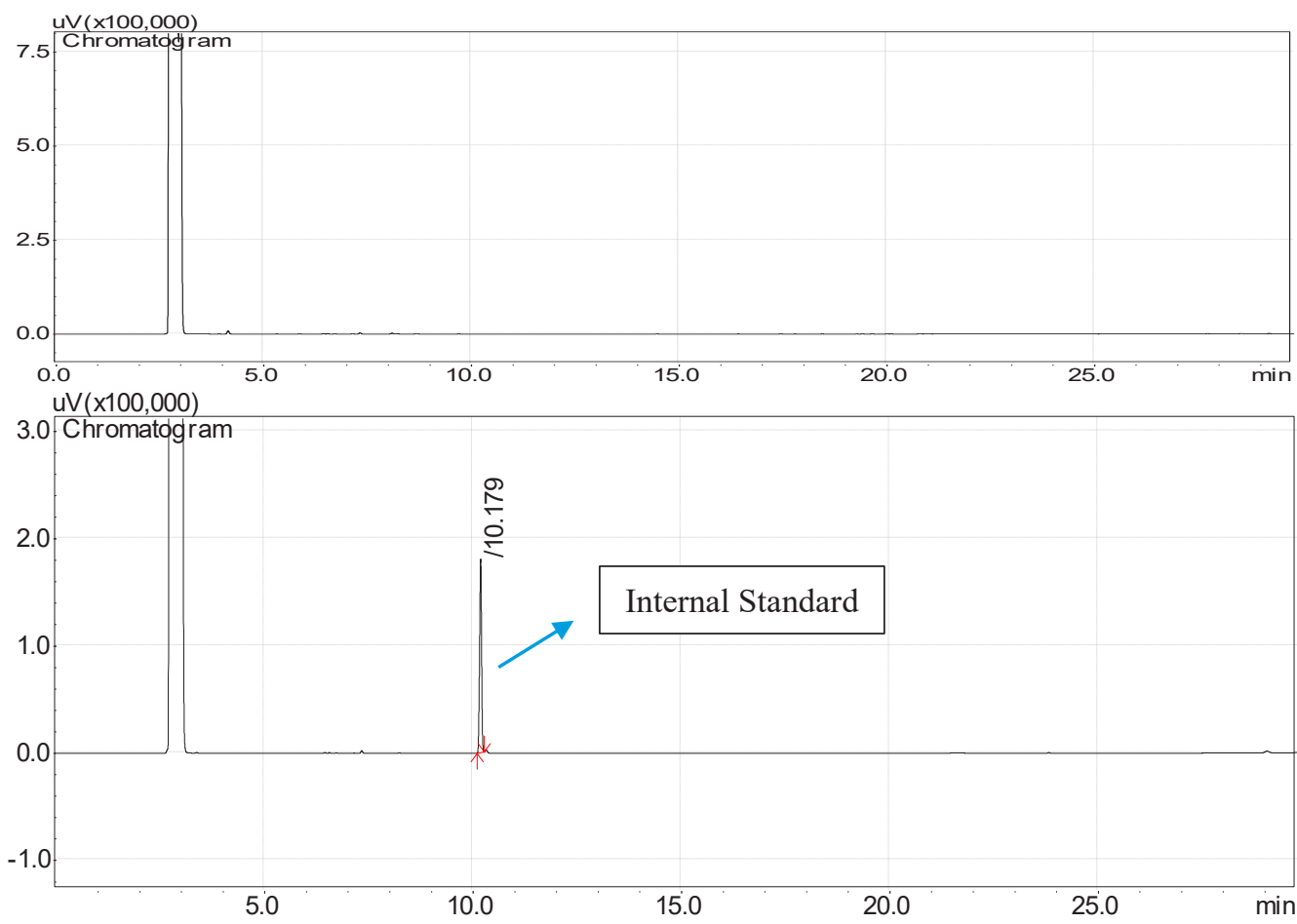

Fig. 3: Blank cotton analysis before and after activation. 


\section{Sampling of Aldehydes in Air or Solution State}

For an analysis of the gas sample, about $50 \mathrm{mg}$ of reagent activated cotton in an open glass vial or beaker was placed in the aldehyde sampling area for a minimum of 1 hour. The sampling area could be any closed or open environment such as a chemical storage area or cupboards, laboratory, and chamber. The sampling of the aqueous solution was done by adding $1 \mathrm{~mL}$ of the filtered liquid sample into $50 \mathrm{mg}$ of reagent activated cotton placed in a PP tube.

Aldehydes content in solids such as polymer was sampled using the setup described under section 2.3.5 for calibration of aldehydes in the vapor state. A known amount of solid sample was weighed, depending upon the content of aldehyde, in a headspace vial, crimped, and heated in an oil bath for one hour at $90^{\circ} \mathrm{C}$. The resulting vapor was collected through a transfer line in another crimped vial containing $50 \mathrm{mg}$ of reagent activated cotton.

\section{RESULTS AND DISCUSSION}

Most of the derivatizing agents for the measurement of aldehyde require strong acidic conditions, limiting its application to samples that are compatible with acid media. Jain et al. (1995) proposed OBA as a derivatizing agent for the ppm level analysis of aldehydes in a neutral medium. However, the application is limited to triethanolamine and requires a long derivatization time. Since the $\mathrm{pH}$ can increase the rate of nucleophilic addition reaction (Fig. 4) between aldehyde and OBA, first, the effect of different $\mathrm{pH}$ was studied.

After that, to improve on the application of this method, experimental conditions were optimized to coat reagent on cotton fiber and for analysis of aldehydes in different matrices such as air, water, and polymer.

\section{Effect of pH}

The effect of $\mathrm{pH}$ on oxime formation was studied using different $\mathrm{pH}$ buffer solutions ranging from $\mathrm{pH} 2.0$ to 8.0. The $\mathrm{pH}$ of the reaction media is essential because a highly acidic $\mathrm{pH}$ may protonate primary amine, whereas neutral/ basic $\mathrm{pH}$ may not facilitate the reaction. Based on the effect of different pH studied (Fig. 5) for both formaldehyde and acetaldehyde derivatization, the maximum conversion to the OBA-FA ( $O$-benzyl hydroxylamine-formaldehyde) derivative was observed between $\mathrm{pH} 4$ to 7 and for the OBA-AA<smiles>NOCc1ccccc1</smiles><smiles>[R]C=O</smiles>

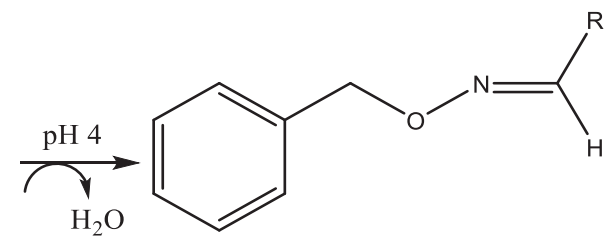

Fig. 4: Reaction of $O$-benzyl hydroxylamine hydrochloride with an aldehyde at the buffer of $\mathrm{pH} 4.0$.

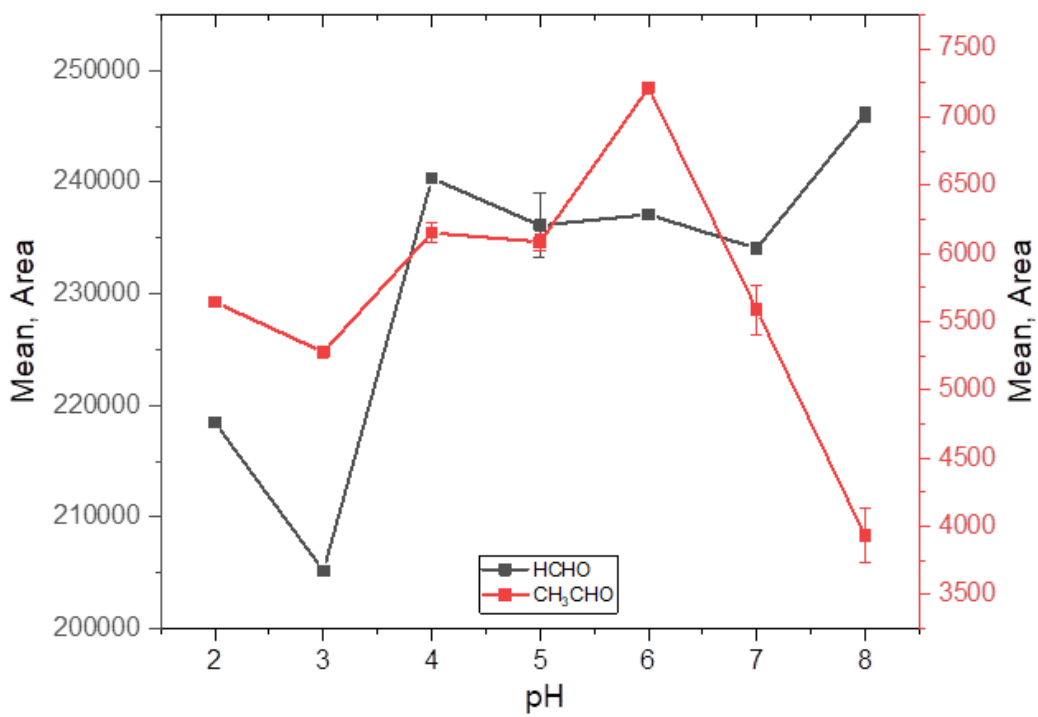

Fig. 5: pH optimization for formaldehyde and acetaldehyde. 
(O-benzyl hydroxylamine -acetaldehyde) derivative was found between $\mathrm{pH} 4$ to 6 .

It is apparent that below $\mathrm{pH} 2$ the protonation of amine or above $\mathrm{pH} 7$ non-ionization of the carbonyl group of aldehyde are two rate-determining steps. The buffer of $\mathrm{pH} 4.0$ was finalized as the reaction medium.

\section{Optimization of Reaction Time}

At $\mathrm{pH} 4$, the time required for derivatization was studied by measuring the product at different intervals (Fig.6). It was found that the reaction is instantaneous and completes anywhere between 5 to 15 minutes.

However, when the same solution was kept for longer than 15 minutes, the product tends to degrade. This tendency is because FA/AA-OBA derivative, which is Schiff's base, is reversible in the presence of water. Therefore, within 10-15 minutes of reaction time, $1 \mathrm{~mL}$ of hexane was added to extract the Schiff's base, thereby increasing the product stability.

\section{Cotton Weight Optimization}

Since cotton is lightweight and bulky, the weight of cotton is crucial for a reproducible result. The different values of the known weight of reagent activated cotton fiber (20 mg to 200 $\mathrm{mg}$ ) were taken in a PP tube and added to a fixed concentration of standard FA-AA mixture. The effect of different weights of reagent activated cotton on the aldehyde response (Fig. 7) shows the optimum weight of cotton required.

Above $50 \mathrm{mg}$ of the activated cotton, the duration of the Schiff base desorption becomes impractical. Due to a large surface area, it bulges after absorption, and the more amount

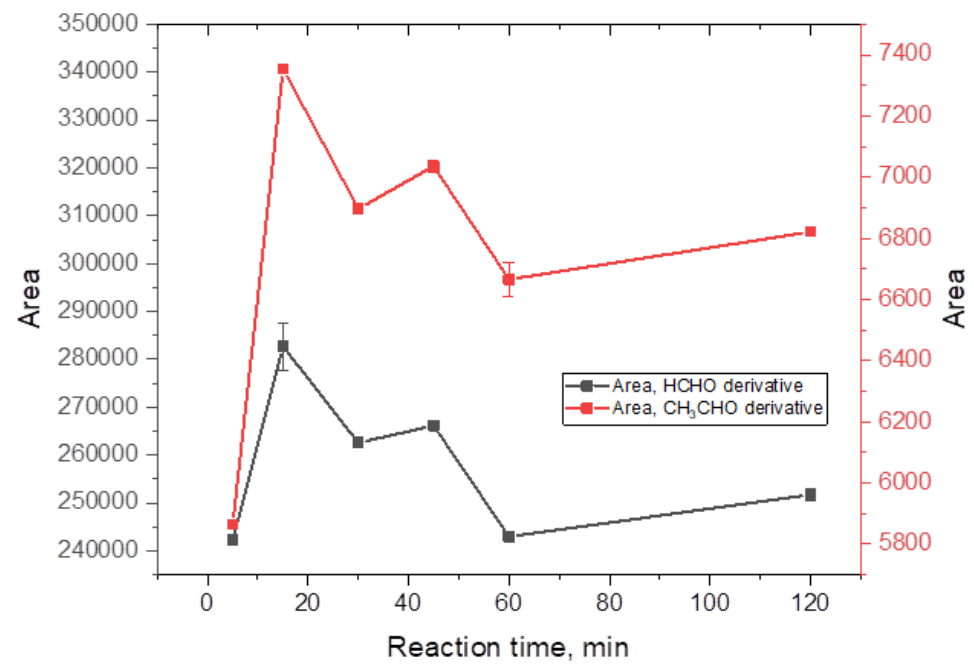

Fig. 6: Reaction time optimization for formaldehyde and acetaldehyde.

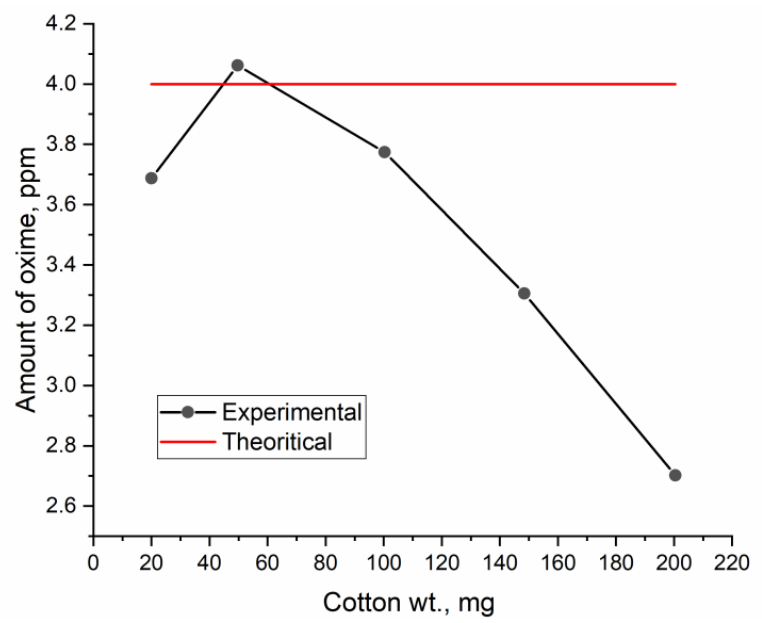

Fig. 7: Cotton weight optimization for formaldehyde and acetaldehyde. 
of cotton will create challenges for effective extraction or desorption.

\section{Stability of Activated Cotton and the Derivatized Product}

The study of the stability of the reagent absorbed cotton fiber and the derivatized product (oxime), carried out at different intervals of time and days, is shown in Fig. 8.

It shows that the cotton activated with OBA was stable for many days; however, the derivative is stable for at least $24 \mathrm{Hrs}$. The representative chromatogram (Fig. 9) shows two peaks for the AA-OBA product, which are geometrical isomers, and the area of both the peaks was added for calculating.
The blank reagent activated cotton fiber analysis rules out any adsorption of aldehydes from the atmospheric air, which contains some ppb level of aldehydes. We have not observed any peaks related to aldehydes during experiments in the blank injections, which were subjected to the same procedures during quantification. The coefficient of determination, $R^{2}>0.99$ (Fig. 10), was achieved for aldehydes in both liquid and vapor in a concentration range of 0.1-1.1 ppm.

The linearity curve indicated that the solubility of aldehyde O-benzyl oxime derivative in water, particularly $1 \mathrm{~mL}$ of $0.15 \mathrm{M} \mathrm{H}_{2} \mathrm{SO}_{4}$, is consistent, reproducible, and no other interferences were observed. The analytical method was validated for the below-mentioned parameters, as per the

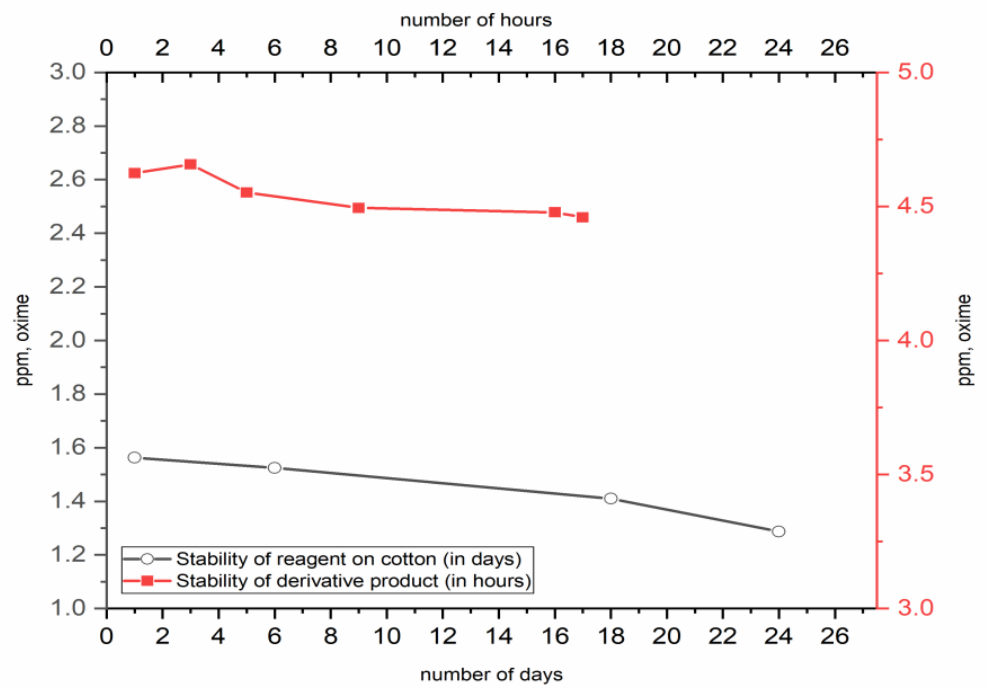

Fig. 8: Pre-reagent absorbed cotton and derivatized product oxime stability study.

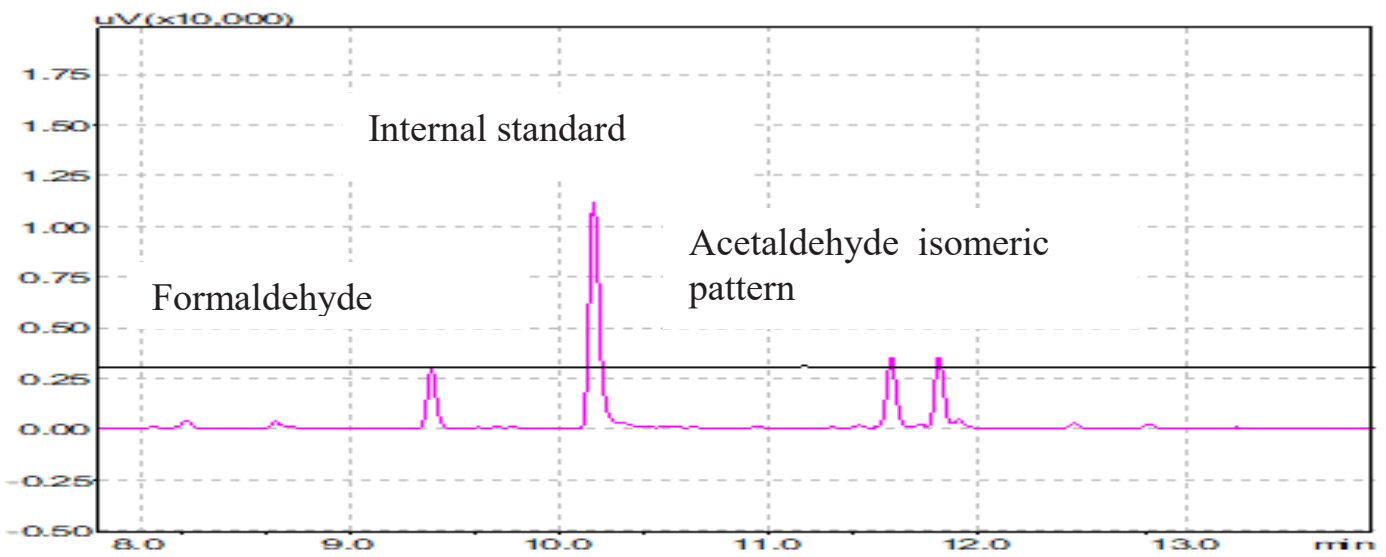

Time in minutes

Fig. 9: GC trace for formaldehyde and acetaldehyde in presence of internal standard. 


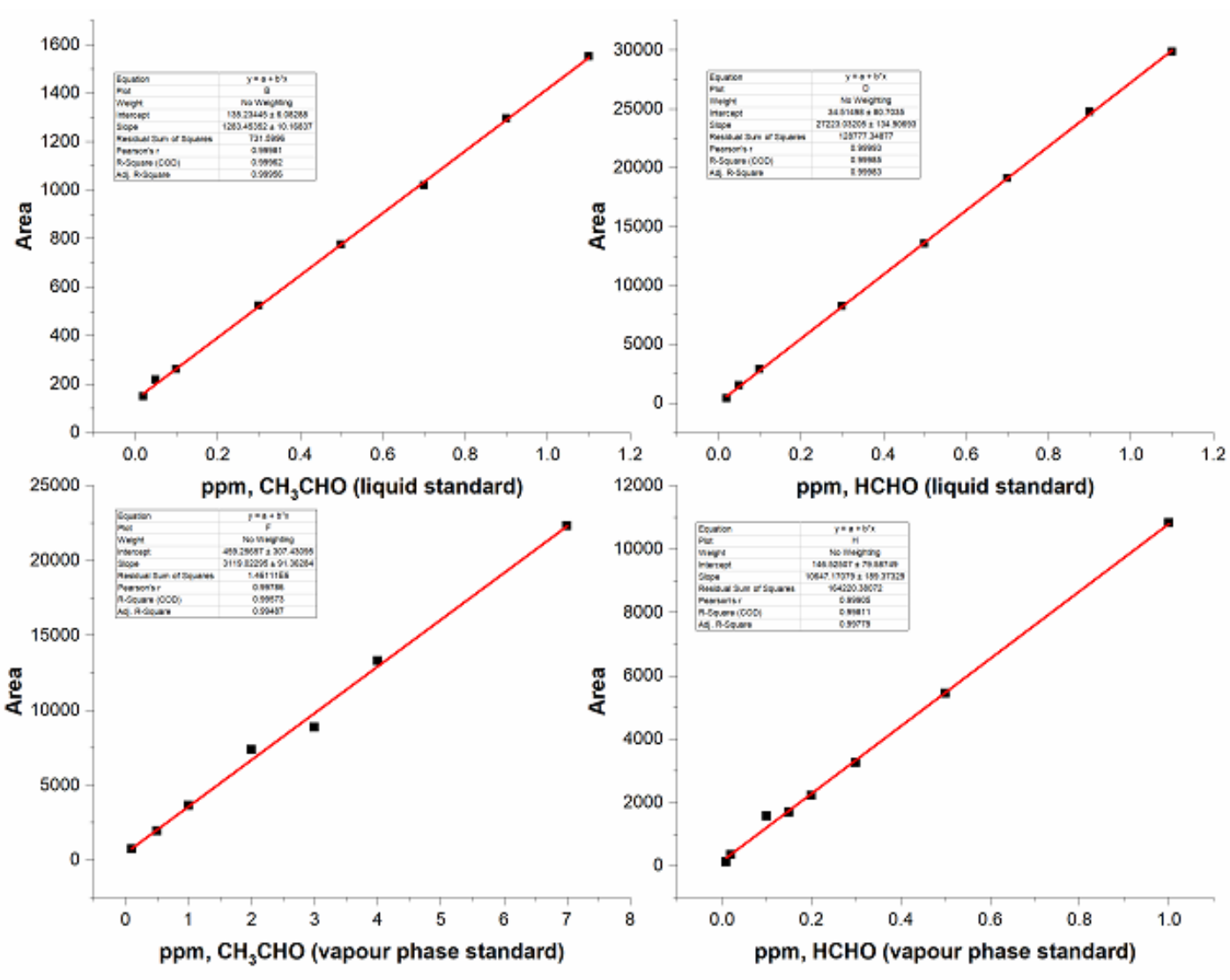

Fig. 10: Linearity graphs in solution phase and vapor phase for formaldehyde and acetaldehyde.

ICH guidelines [35]. The range, regression coefficient, limit of detection (LOD), and limit of quantification (LOQ), accuracy, and precision of the methods are included in Table 1.

Applications: Aldehydes were measured in an effluent treatment plant, laboratory environment, inside a chemical storage refrigerator, and in a polymer sample, following the sampling procedure described in section 2.3.5. The results are shown in Table 2.

The methods for the quantification of carbonyl compounds in the chemical field, specifically aldehydes, have been established by researchers and industries. Many methods using chromatographic techniques are useful in quantifying aldehydes at a meager $\mathrm{ppm} / \mathrm{ppb}$ limit of detection and quantification levels within reasonable ranges. However, in practice, industries or researchers are facing challenges to meet the other critical criteria like cost, time, and waste generation. Aldehyde quantification in indoor air or food matrix using solid-phase, microextraction followed by on-fiber derivatization or 2,4-dinitrophenylhydrazine technique enables to detect in ppb level (Bourdin \& Desauziers 2014). However, it will generate a large amount of waste since it needs lots of solvents for washing of sorbents and very laborious. The derivatization techniques using acetoacetanalide

Table 1: Analytical method validation parameters for formaldehyde and acetaldehyde in solution and vapor phase.

\begin{tabular}{|llllllll}
\hline \multirow{2}{*}{ Method } & \multicolumn{2}{l}{ Coefficient of determination $(\mathrm{R} 2)$ and range } & \multicolumn{2}{c|}{ Detection limit } & \multicolumn{2}{c|}{$\%$ RSD (Precision) } \\
\cline { 2 - 6 } & FA, $(\mathrm{ppm})$ & AA, $(\mathrm{ppm})$ & FA, $(\mathrm{ppb})$ & AA, $(\mathrm{ppb})$ & FA & AA (isomeric) \\
\hline Solution & $0.9999(0.01-1.1)$ & $\begin{array}{l}0.9978 \\
(0.01-1.1)\end{array}$ & 1.5 & 19 & 0.59 & 1.95 & $93.2-102 \%$ \\
Vapour & $0.9990(0.01-1.1$ & $\begin{array}{l}0.9998 \\
(0.01-7)\end{array}$ & 4 & 8 & 0.22 & 1.45 & $96.2-101.98 \%$ \\
\hline
\end{tabular}


Table 2: Summary of representative sample analysis in various matrices.

\begin{tabular}{|c|c|c|c|c|c|}
\hline \multirow[t]{2}{*}{ Sample } & & \multicolumn{2}{|c|}{ Solution analysis } & \multicolumn{2}{|c|}{ Vapor analysis } \\
\hline & Mode of study & $\begin{array}{l}\mathrm{FA},(\mathrm{RSD}) \\
\mathrm{n}=3\end{array}$ & $\mathrm{AA},(\mathrm{RSD}) \mathrm{n}=3$ & $\begin{array}{l}\mathrm{FA},(\mathrm{RSD}) \\
\mathrm{n}=3\end{array}$ & $\begin{array}{l}\mathrm{AA},(\mathrm{RSD}) \\
\mathrm{n}=3\end{array}$ \\
\hline ETP & Liquid & $0.59 \mathrm{ppm}(1.45 \%)$ & $16.4 \mathrm{ppm}(2.3 \%)$ & Not Applicable & Not Applicable \\
\hline CSR & Vapour & Not Applicable & Not Applicable & $0.53 \mathrm{ppm}(0.71 \%)$ & $0.36 \mathrm{ppm}(0.65 \%)$ \\
\hline Lab / cabinet & Vapour & Not Applicable & Not Applicable & $\begin{array}{l}\text { Less than } \\
4 \mathrm{ppb}\end{array}$ & $\begin{array}{l}\text { Less than } \\
8 \mathrm{ppb}\end{array}$ \\
\hline Polymer (PET) & Vapour & Not Applicable & Not Applicable & Not Applicable & $0.21 \mathrm{ppm}(0.51 \%)$ \\
\hline
\end{tabular}

or O-(2,3,4,5,6-pentafluorobenzyl) hydroxylamine are used to monitor aldehydes in detergents, cosmetic products, raw water during ozonation, and gaseous carbonyl compounds in the air are describing only for specific customized applications. They are not cost-effective and involve cumbersome processes. The metric effects, challenges with the stability of SPME fibers, mass source modification for the specific application are also observed in some of these techniques, and few are very limited to only the lab/research field. The reagent O-benzylhydroxylamine hydrochloride used for the determination of aldehydes in Triethanolamine work reported the very loner derivatization time of $2 \mathrm{hrs}$. The pre-column derivatization followed by fluorescence detection is very sensitive to $\mathrm{pH}$, temperature, and time. The methods developed to determine aldehydes in cosmetics, detergents, indoor air using spectroscopy and proton NMR techniques are not sensitive for low-level detection and observed high standard deviation.

\section{CONCLUSIONS}

Based on the challenges observed in the literature methods including the green analytical chemistry challenges, the new methodology using cotton fiber is established for the quantification of formaldehyde and acetaldehyde. The method can be applied to any other aldehydes and used in many applications. The new method has been reported for the pre-concentration and determination of acetaldehyde and formaldehyde using $O$-benzylhydroxyl amine treated cotton, which is subsequently extracted and analyzed using simple gas chromatography with a flame ionization detector from various matrices. The stability of the RACF with and without captured aldehydes was 17 days and $24 \mathrm{Hrs,}$ respectively, qualifying the technique for field applications. The advantages of the reported method are the avoidance of separate reagent preparation, ease of sampling, and low monetary requirements. The process complies with green analytical chemistry principles, such as using biodegradable material, reducing a large amount of waste generation for sample preparation/analysis, using water-soluble reagents in a minimal amount, and less expensive. By using the innate high adsorption capacity of the cotton, the reagent activated cotton is conveniently used to measure aldehydes in various sample matrices such as air, aqueous, and polymer sample. The integration regarding sampling and in-situ detection would make advanced techniques further attractive for a large domain of applications. This blending may be achieved by having cotton activated with a 'marker' within the derivatizing agent that can be measured under IR (Infrared), UV, or fluorescence detector. The RACF technology could be explored to other analytes determination using respective derivatizing agents or chemicals.

\section{REFERENCES}

Bourdin, D. and Desauziers, V. 2014. Development of SPME on-fiber derivatization for the sampling of formaldehyde and other carbonyl compounds in indoor air. Anal. and BioAnal. Chem., 406: 317-328.

Chung, P.R., Tzeng, C.T., Ke, M.T. and Lee, C.Y. 2013. Formaldehyde gas sensors: A review. Sensors, 13: 4468-4484.

CPMP/ICH/381/95 Validation of analytical methds and terminology, ICH topic Q2A 1995. http://www.pharma.gally.ch/ich/q2a038195en.pdf

Dochia, C. M., Sirghie, R.M. and Kozłowski, R. 2012. Handbook of natural fibers. Wood-Head Pub. Ser. in Textiles, 1: 11-23.

Eugenia, C. and Silva, B.M. 2010. Analysis of low-molecular mass aldehydes in drinking waters through capillary electrophoresis with laser-induced fluorescence detection. Electrophoresis, 31: 2028-2036.

Gholami, A., Mohsenikia, A. and Masoum, S. 2016. Determination of very low level of free formaldehyde in liquid detergents and cosmetic products using photoluminescence method. J. Anal Methods Chem, 50(3): 1014-1022.

Gosetti, F., Chiuminatto, U., Mazzucco, E., Robotti, E., Calabrese, G., Gennaro, M.C. and Marengo, E. 2011. Simultaneous determination of thirteen polycyclic aromatic hydrocarbons and twelve aldehydes in cooked food by an automated online solid-phase extraction ultra-high-performance liquid chromatography-tandem mass spectrometry. J. Chromatogr. A, 1218: 6308-6318.

Guan, X. and Rubin, E. 2012. An optimized method for the measurement of acetaldehyde by high-performance liquid chromatography. Alcohol Clin. Exp. Res., 36: 398-405.

ICH guidelines-http//www.fda.gov/cder/guida, (2016), US, Q7 Good Manufacturing Practice Guidance for Active Pharmaceutical Ingredients, Guidance for Industry

Jain, V. and Thielen, D. 1995. Determination of aldehydes in the basic medium by gas chromatography using O-benzylhydroxylamine derivatization. J. Chromatogr. A, 709(2): 387-392.

Jeong, H.S., Chung, H., Hoon Song, S., Kim, C. Joon-Goo, L. and Young- 
Suk, K. 2015. Validation and determination of the contents of acetaldehyde and formaldehyde in foods. Toxicol. Res., 31: 273-278.

Koziel, J. A., Noah, J. and Pawliszyn, J. 2001. Field sampling and determination of formaldehyde in indoor air with solid-phase microextraction and on-fiber derivatization. Environ. Sci. Technol., 35: 1481-1486.

Kuballa, T., Mildau, G., Kratz, E., Keck-Wilhelm, A., Tschiersch, C. and Lachenmeier, D.W. 2013. Formaldehyde in hair straightening products: Rapid ${ }^{1} \mathrm{H}$ NMR determination and risk assessment. Intl. J. of Cos. Sci., 35: 201-206.

Lin, Y.L., Wang, P.Y., Hsieh, L.L., Ku, K.H., Yeh, Y.T. and Wu, C.H. 2009. Determination of linear aliphatic aldehydes in heavy metal containing waters by high-performance liquid chromatography using 2,4-dinitrophenylhydrazine derivatization. J. Chromatogr. A, 1216: 6377-6381.

Mumiye, A., Ogunwale, Mingxiao Li., Mandapati, V., Ramakrishnan, R., Yizheng, C., Michael, H., Nantz, Daniel, J., Conklin, R. and Xiao-An, F. 2017. Aldehyde detection in electronic cigarette aerosols. ACS Omega, 2: 1207-1214.

Nawrocki, J., Kalkowska, I. and Dabrowska, A. 1996. Optimization of solid-phase extraction method for analysis of low-ppb amounts of aldehydes-ozonation by-products. J. Chromatogr. Sci., 749: 157-163.

Pang, X., Lewis, A.C. and Ródenas-García, M. 2013. Microfluidic lab-ona-chip derivatization for gaseous carbonyl analysis. J. Chromatogr. A, 1296: 93-103.

Qing, Y., Zheng, D., Liu, L. M. and Hong., L. 2011. Rapid analysis of aldehydes by simultaneous microextraction and derivatization followed by GC-MS. J. of Sepr. Sci., 34: 1607-1612.

Rivero, R.T. and Topiwala, V.J. 2004. Quantitative determination of formaldehyde in cosmetics using combined headspace-solid-phase micro extraction-gas chromatography. Cosmet Sci., 55: 343-350.

Rosenberger, W., Beckmann, B. and Wrbitzky, R. 2016. Airborne aldehydes in cabin-air of commercial aircraft: Measurement by HPLC with UV absorbance detection of 2,4-dinitrophenylhydrazones, J. Chromatogr. Sci. B, 1019: 117-127.

Sakaia, T., Tanaka, S.I., Teshima, N., Yasuda, S. and Ura, N. 2002. Fluorimetric flow injection analysis of trace amount of formaldehyde in the environmental atmosphere with 5,5-dimethylcyclohexane-1,3-dione, Talanta, 58: 1271-1278.

Sampson, M.M., Chambers, D.M., Pazo, D.Y., Moliere, F., Blount, B.C. and Watson, C.H. 2014. Simultaneous determination of four aldehydes in the gas phase of mainstream smoke by headspace gas chromatography-mass spectrometry, Anal. Chem., 86: 7088-7095.
Sang, H. J. and Kim, K.H. 2016. Development of a sampling method for carbonyl compounds released due to the use of electronic cigarettes and quantitation of their conversion from liquid to aerosol, J. Chromatogr. A, 1429: 369-373.

Suze, M., Leeuwen, V., Hendriksen, L. and Uwe, K. 2004. Determination of aldehydes and ketones using derivatization with 2,4-dinitrophenylhydrazine (DNPH) and liquid chromatography/atmospheric pressure photoionization-mass spectrometry (LC/APPI-MS), J. Chromatogr. A, 1058: 107-112.

Szulejko, J. E. and Kim, K. H. 2015. Derivatization techniques for determination of carbonyls in air. Trends Anal. Chem., 64: 29-41.

Textile Fashion Study. 2012. Cotton-fiber-manufacturing physical and chemical properties. http://textilefashionstudy.com/cotton-fiber-physical-and-chemical-properties-of-cotton/

Tsai, S.W. and Chang, C.M. 2003. Analysis of aldehydes in water by solid-phase microextraction with on-fiber derivatization, J. Chromatogr. A, 1015: 143-150.

Valentina, L., Christova, B., Julieta, A. and Tishkova, V.G. 2014. Health risks associated with PET bottled mineral waters and beverages: Overview, analysis, and evaluation. J. Environ. Sci., Comp. Sci. Eng.Technol, 3(4): 1856-1876.

Vander, H., Nguyet, A.N., Detaevenier, M.R., Massart, D.L. and Plaizier, V. 2002. Simultaneous determination of ketoconazole and formaldehyde in a shampoo: Liquid chromatography method development and validation. J. Chromatogr A., 958: 191-201.

Vanessa, M.O. and Zenilda, L.C. 2013. Analytical methods to assess carbonyl compounds in foods and beverages. Chem. Soc., 24: 1711-1718.

Veloso, M.C.C., Silva,V.M., Santos, G. V. and Andrade, J. B. 2001. Determination of aldehydes in fish by high-performance liquid chromatography, J. Chromatogr. Sci. 39: 173-176.

World Health Organization- International Agency for Research on Cancer (WHO_IARC). 2002. IARC Monographs on the Evaluation of Carcinogenic Risks to Humans. https://monographs.iarc.who.int/wp-content/ uploads/2018/06/mono81.pdf

Zhang, X., Wang, R., Zhang, Li., Wei, Jianke., Ruan, Y., Wang, W., Houwei, Ji. and Jian, Liu. 2018. Simultaneous determination of four aldehydes in the gas phase of mainstream smoke by headspace gas chromatography-mass spectrometry, Int. J. Anal. Chem., 2019(2): 1-6

Zhao, W., Zhang, Q.B., Lu, S., Sun, Zhang, S. and Zhang, J. 2017. Rapid determination of six low molecular carbonyl compounds in tobacco smoke by the APCI-MS/MS coupled to data mining. J. Anal. Metds. Chem., 1-7. 